\title{
Hidradenitis Süpürativada Cerrahi Tedavinin Başarısı: Geniş Ve Derin Cerrahi Eksizyon
}

\section{Surgical Treatment Success in Hidradenitis Suppurativa: Deep and Wide Surgical Excision}

\section{Fatma BILGEN ${ }^{1}$, Alper URAL ${ }^{1}$, Mehmet BEKERECİOĞLU ${ }^{2}$}

\author{
${ }^{1}$ Yrd. Doç. Dr. Kahramanmaraş Sütçü İmam Üniversitesi Tip Fakültesi Plastik ve Rekonstrüktif Cerrahi AD, KAHRAMANMARAŞ \\ ${ }^{2}$ Prof. Dr. Kahramanmaraş Sütçü İmam Üniversitesi Tip Fakültesi Plastik ve Rekonstrüktif Cerrahi AD, KAHRAMANMARAŞ
}

\section{Özet}

Amaç: Hidradenitis süpürativa apokrin ter bezlerinde yerleşen ağrılı, akıntılı apse oluşumları, sinüs, fistül ve skarlar ile çevre dokulara yayılan tekrarlayıcı bir hastalıktır. Etyolojisi kesin olarak bilinmemekle birlikte genetik yatkınlı, hormonal faktörler, obezite ve sigara kullanımı suçlanan faktörlerdir. Bu çalışmada farklı anatomik bölgelerde bulunan ve klinik olarak farklı güvenlik sınırıyla eksizyon uygulanmış hidradenitis süpürativa olgularındaki nüks ve diğer komplikasyon oranlarının araştırılması amaçlanmıştır.

Gereç ve Yöntemler: Bu çalışmada Ocak 2000- Mart 2017 tarihleri arasında plastik cerrahi polikliniğine müracaat eden, medikal tedaviye dirençli, kronik, rekürrens gösteren ve cerrahi tedavi uygulanan 45 hasta lezyonların yerleşim yeri, uygulanan cerrahi yöntemler ve komplikasyonlar açısından retrospesifik olarak değerlendirildi. Etkilenen kıllı bölge inflamasyon görülen çevre dokuların derin fasyaya kadar geniş eksizyonu sonrası oluşan defektler, defektin genişliğine göre primer olarak, erken veya geç dönemde greft uygulanarak veya lokal flepler kullanılarak kapatıldı

Bulgular: Lezyonlar en sık perianal/genital $(n=35, \% 41,8)$ bölgede yerleşim gösterirken, bunu sırasıyla koltuk altı $(\mathrm{n}=21, \% 25.6)$, gluteal bölge ( $n=21, \% 25.6)$ ve meme çevresi ( $n=3, \% 2.7)$ takip etmekteydi. Lezyonların 36'sında geniş ve derin eksizyonu takiben oluşan defekt alanları lokal flepler ile kapatılırken, 16 lezyonun eksizyonu sonrası oluşan defekt alanları kısmi kalınlıklı deri greftleri ile kapatıldı. 26 lezyona eksizyon sonrası primer onarım yapıldı.

Sonuç: İntermammarial bölgede lezyonu olan 2 hastada ve perianal yerleşimli lezyonu olan 3 hastada lezyon sınırında yapılan eksizyonlar sonrası nüks görüldü. Toplamda hastalarda nüks oranı $\% 11,1$ olarak tespit edildi ve bu hastalara daha geniş cerrahi sınırla reeksizyon yapıldı. Bu çalışmanın amacı hidradenitis süpürativa tedavisinde geniş ve derin cerrahi eksizyonu önemini vurgulamaktır.

Anahtar Kelimeler: Hidradenit Süpüratif; Nüks

\section{GİRIS}

Hidradenitis süpürativa (HS), apokrin bezlerin kronik, tekrarlayan, abse ve sinüslerin eşlik ettiği inflamatuvar bir hastalığıdır. Klinik olarak ilk kez 1839'da Valpeau tarafından tanımlanmış olup, hastalığın temelde ter bezlerinin iltihabına bağlı olduğu 1854' de Verneuil tarafından bulunmuştur (1-3). Hidradenitis süpürativanın görülme sıklığı tam olarak bilinmemekle birlikte yaklaşık olarak 300-600 erişkinden birinde olduğu tahmin edilmektedir. HS'nin puberteden önce ve 40 yaşından sonra görülmesi nadir olup her iki cinste de sıklıkla 2. ve 3. dekatta ortaya çıkmaktadır. Kadınlarda

\section{Abstract}

Objective: Hidradenitis suppurativa is a recurrent disease that spreads to the surrounding tissues with painful, smooth abscess formation, sinus, fistula and scarring located in the apocrine sweat glands. Although etiology is not known precisely, genetic predisposition, hormonal factors, obesity and smoking are the accused factors. In this study, we aimed to investigate the recurrence and other complication rates of hydradenitis suppurativa in different anatomical regions with excision with clinically different safety margin.

Materials and Methods: In this study, 45 patients who were admitted to plastic surgery clinic between January 2000 and March 2017 with medical treatment resistant, chronic, recurrence and surgical treatment were evaluated retrospectively in terms of resection site, applied surgical methods and complications. The affected hair follicles were enlarged to the deep fascia of inflamed surrounding tissues, and defects were localized according to the width of the defect, either early or late using grafts or using local flaps.

Results: The lesions were most commonly located in the perianal / genital area $(\mathrm{n}=35,41.8 \%)$, followed by the axillary $(\mathrm{n}=21,25.6 \%)$, gluteal area $(n=21,25.6 \%, 2.7 \%)$. In 36 of the lesions, the defect areas following wide and deep excision were covered with local flares, while the defect areas after excision of the 16 lesions were covered with partial thickness skin grafts. 26 lesions were primary repair after excision.

Conclusion: In 2 patients with intermammary lesions and 3 patients with perianal lesions, recurrences were observed after excision on the lesion border. In total, the recurrence rate was found to be $11.1 \%$ in patients and this disease was re-esced with wider surgical margin. The aim of this study is to emphasize the importance of extensive and profound surgical excision in the treatment of hydradenitis suppurativa.

Key Words: Hydradenite Suppurative; recurrence, surgery

erkeklerden daha sık görülmesine rağmen, perianal bölge yerleşimi erkeklerde 2 kat fazladır (4).

Kesin etiyoloji bilinmemekle birlikte genetik yatkınlık, hormonal faktörler, obezite, diabetes mellitus, sigara kullanımı ve kötü hijyen öne çıkan nedenler arasindadir (4-8).

Etiyolojide hangi faktör olursa olsun, hastalığın temel mekanizması foliküler epitelin hiperkeratozisine bağlı keratin tıkaçlarla apokrin bez duktuslarının tıkanması, apokrin ter bezlerinin süperenfeksiyonu ve enfekte bezlerin rüptürü sonucu enfeksiyonun

\begin{tabular}{|c|c|c|}
\hline İletişim: & $\begin{array}{l}\text { Dr. Fatma Bilgen, KSÜ Tip Fakültesi Plastik ve Rekon- } \\
\text { strüktif Cerrahi AD, KAHRAMANMARAŞ }\end{array}$ & 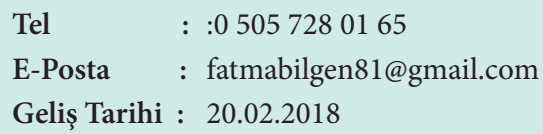 \\
\hline DOI: & DOI: $10.17517 /$ ksutfd.396944 & Kabul Tarihi : 09.03.2018 \\
\hline
\end{tabular}


subkutan plana yayılması ile ortaya çıkmaktadır. En sık olarak apokrin ter bezlerinin bulunduğu aksiller, inguinoperineal, gluteal, ense ve uyluk içyüzünde görülmektedir $(9,10)$.

Klinik olarak akne tarzında folllikülit olarak başlayan tablo, uzun dönemde sekonder bakteriyel enfeksiyonların eklenmesiyle tekrarlayan, pürülan materyal içeren dermal veya subdermal abse formasyonlarına ilerlemektedir (Resim 1). Her nüks sonrası, deri altı dokudaki kaviteler ilerler ve birbirleriyle bağlantılı sinüs traktları ve fistül oluşumlarına yol açarak enfeksiyon çevre dokulara yayılır (Resim 2) (11-14).

Resim 1. Gluteal bölgede yaygın pürülan enfeksiyon ve fistül ile seyreden Hurley evre 3 lezyonu olan hasta.

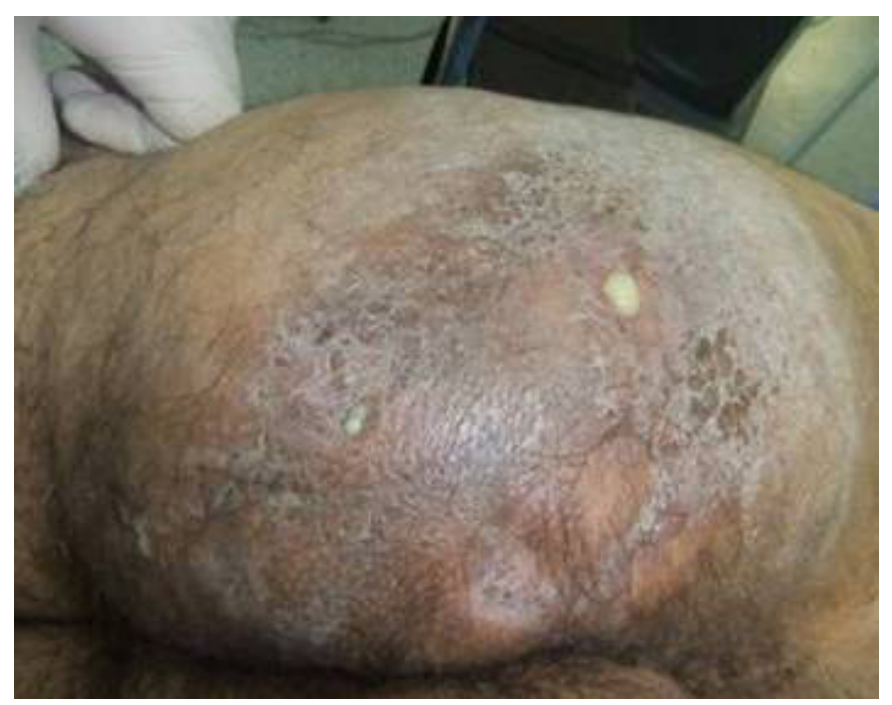

Resim-2: Pubis üst bölümde deri katlantıları alanına uyan bölgelerde hidradenitis süppürativa. Lezyonun ameliyat öncesi ve geniş eksizyonu sonrasi görüntüsü izlenmektedir.

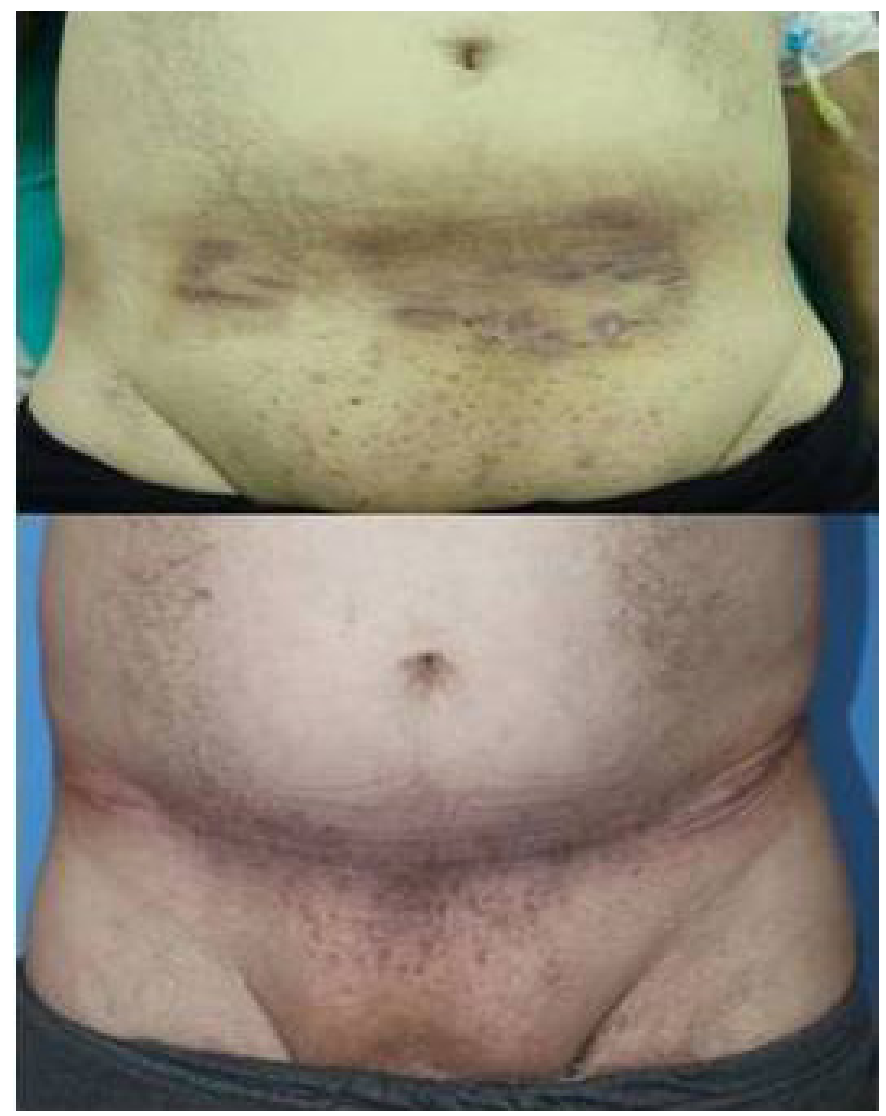

Hidradenitis süpürativa erken evre tedavisinde topikal ve sistemik antibiyotik kullanımı yaygın medikal tedavi olarak kullanılırken, kronik, inatçı ve ilerlemiş olgularda tutulan follikülit alanlarının ve sinus traktlarının cerrahi eksizyonu kaçınılmaz olmaktadır (3, 15-18)

$\mathrm{Bu}$ çalışmada farklı anatomik bölgelerdeki hidradenitis süpürativa olgularında uygulanan cerrahi tedavi seçenekleri ile nüks görülme ve komplikasyon gelişme oranları retrospesifik olarak değerlendirilmiştir.

\section{GEREÇ VE YÖNTEMLER}

Bu çalışmada Ocak 2000- Mart 2017 tarihleri arasında polikliniğimize müracaat eden, medikal tedaviye dirençli, kronik, rekürrens gösteren ve cerrahi tedavi uygulanan 45 hasta retrospesifik olarak değerlendirildi. Hastaların hepsinden operasyon öncesi detaylı bilgilendirilmiş onam formu alındı.

Hastaların yaş, cinsiyet, eşlik eden risk faktörleri, anatomik lokalizasyon, hastalığın süresi, cerrahi tedavi şekli, komplikasyon ve takip süreleri değerlendirilip, nüks oranları ve cerrahi teknikler açısından karşılaştırılmıştır.

Hastalığın evrelendirilmesi Hurley sinıflamasına göre yapildi (18).

Evre 1; Sinus traktusu ve skatrizasyon olmaksızın bir ya da daha fazla abse formasyonu

Evre 2; Sinüs traktı ve skar oluşumu ile bir veya daha fazla abse formasyonu

Evre 3; Hastalıklı bölgede çoklu birbiri ile ilişkili traktuslar ve abselerin olduğu durumu içermektedir.

Hastaların tümü genel anestezi altında operasyona alındı. Etkilenen kıllı bölge inflamasyon görülen çevre dokuların derin fasyaya kadar geniş eksizyonu sonrası oluşan defektler, defektin genişliğine göre primer olarak, erken veya geç dönemde greft uygulanarak veya lokal flepler kullanılarak kapatıldı ( Resim 3, 4).

Yaygin perianal/perineal lezyonu olan 4 hastaya genel cerrahi tarafından kolostomi açıldı ve tedavinin tamamlanmasını takiben kolostomiler 3. ayda kapatıldı. Bütün hastalara ameliyattan üç gün önce kültür sonucuna göre antibiyotik başlandı ve postoperatif 5 gün tedaviye devam edildi. Ayrica, perianal lezyonları olan hastalara günde iki kez oturma banyosu uyguland.

\section{BULGULAR}

Toplamda 45 hastada 80 ilerlemiş, kronik, rekürrens gösteren hidradenitis süpürativalı bölgeye cerrahi tedavi uygulandi. Çalışmaya kabul edilen 45 hastanın 20'si kadın, 25'i erkek ve yaş ortalaması 37,6 (15-78 yaş) idi. Hastalı̆̆ın başlama yaşı erkeklerde ortalama 23.4 yıl (1634, SD: 5,6), kadınlarda ise ortalama 19.7 yll (14-30, SD: 6,0 ) olarak belirlendi.

Erkek hastalarda ilk lezyondan itibaren cerrahi eksizyon için geçen ortalama süre 19,8 y1l (1-32 yll, SD: $8,5)$ iken bu süre kadınlarda 8,4 yıl (0-14 yıl, SD: 4,1) idi.

Eşlik eden potansiyel risk faktörleri gözden geçirildiğinde; 20 (\% 80) erkek hastanın ve 6 (\% 30) kadın hastanın günde bir paketten fazla sigara kullanıcısı olduğu, tüm hastaların vücut kitle indeksilerinin ortalamasının erkeklerde 29. 5 (25-35), kadınlarda 33, 5 (28-45) olduğu tespit edildi. Sadece 1 kadın hastada aile 
Resim-3: İnguinal bölgeden perineal bölgeye uzanan lezyonu olan hastaya eksizyon ve primer onarım sonrası erken dönemde dikiş hattında ayrilma

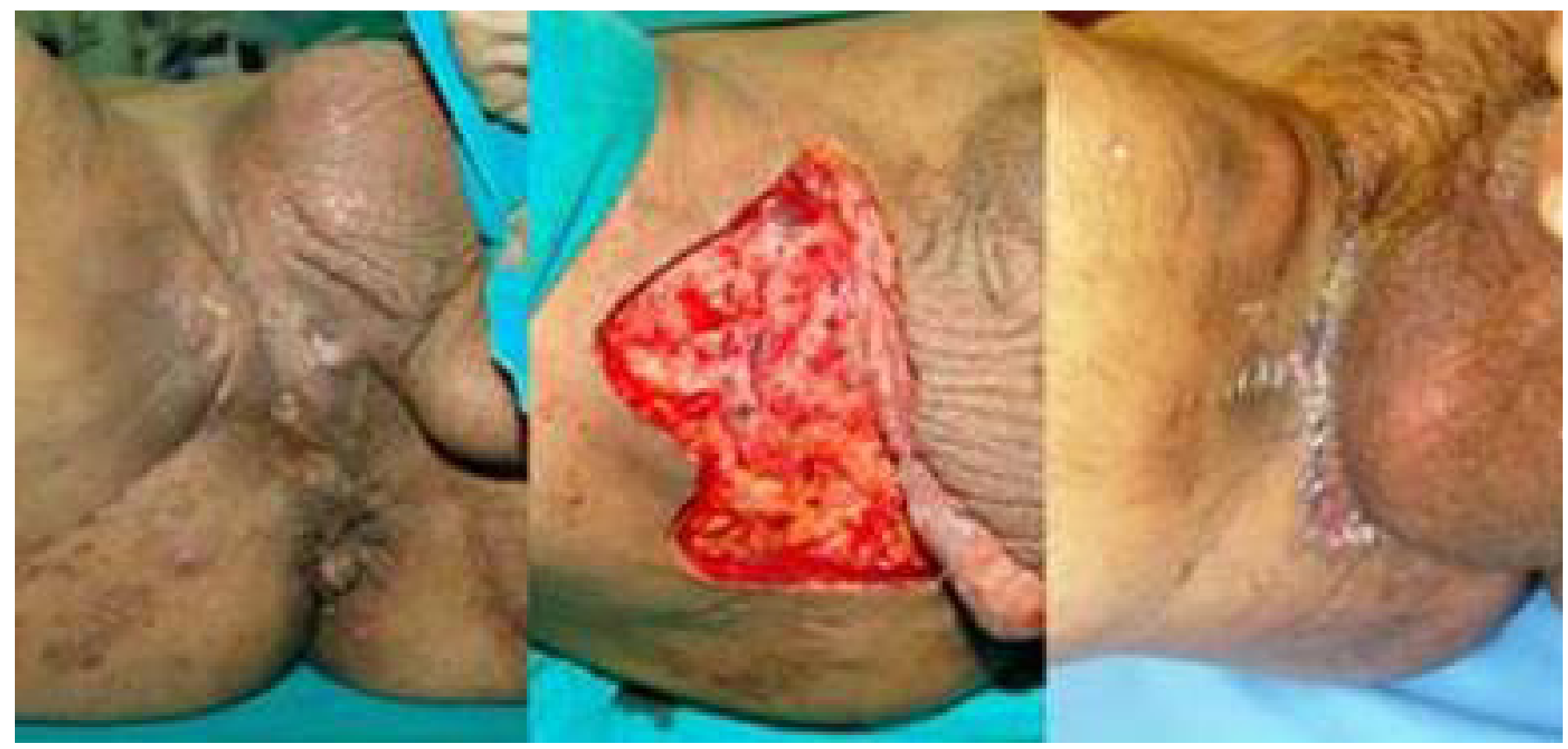

Resim-4: Gluteal bölgedeki lezyonun geniş eksizyonu sonrası lokal fleple onarim yapılan hasta.

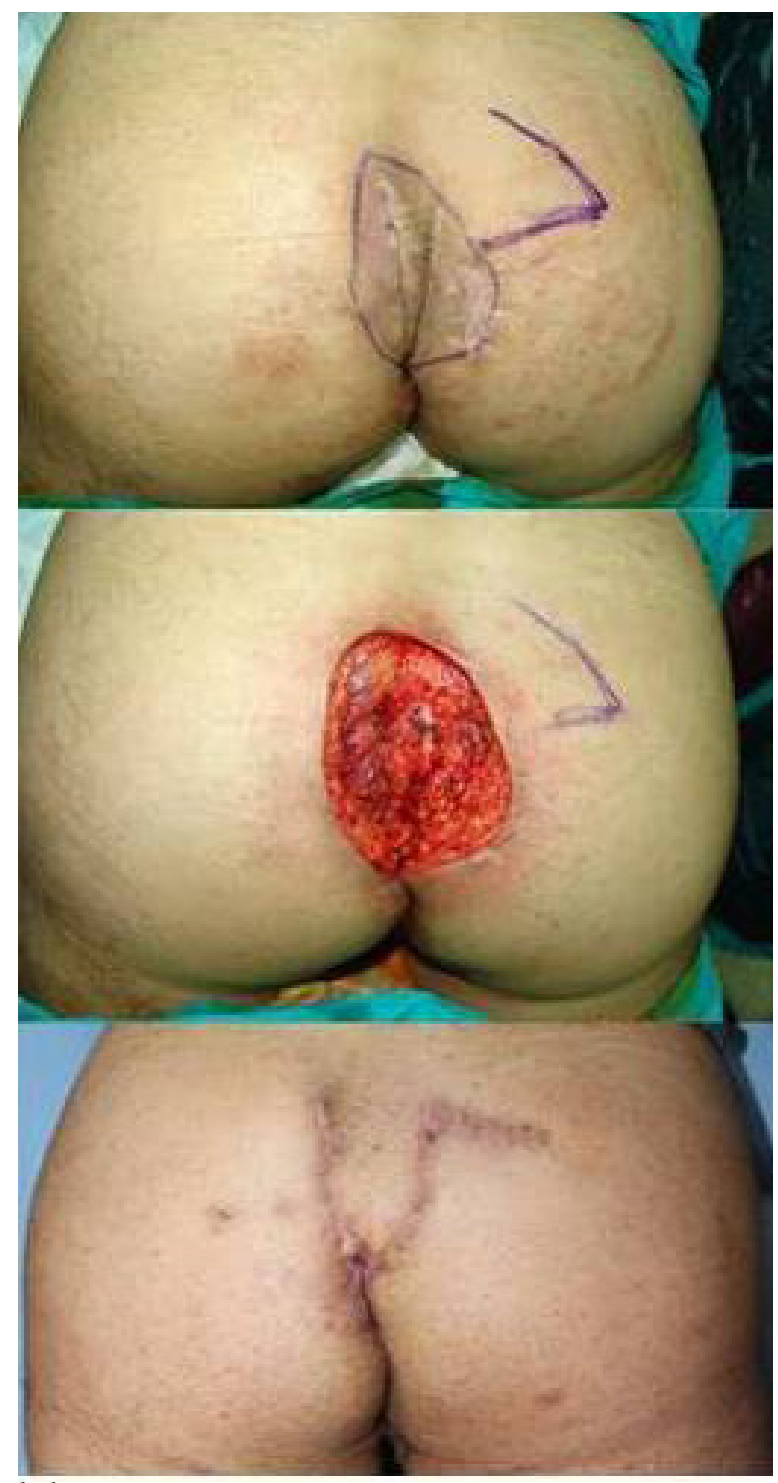

hikâyesi mevcuttu.
Resim-5: Gluteal bölgedeki lezyon için geniş eksizyon sonrası lokal fleplerle onarım yapılan hasta.

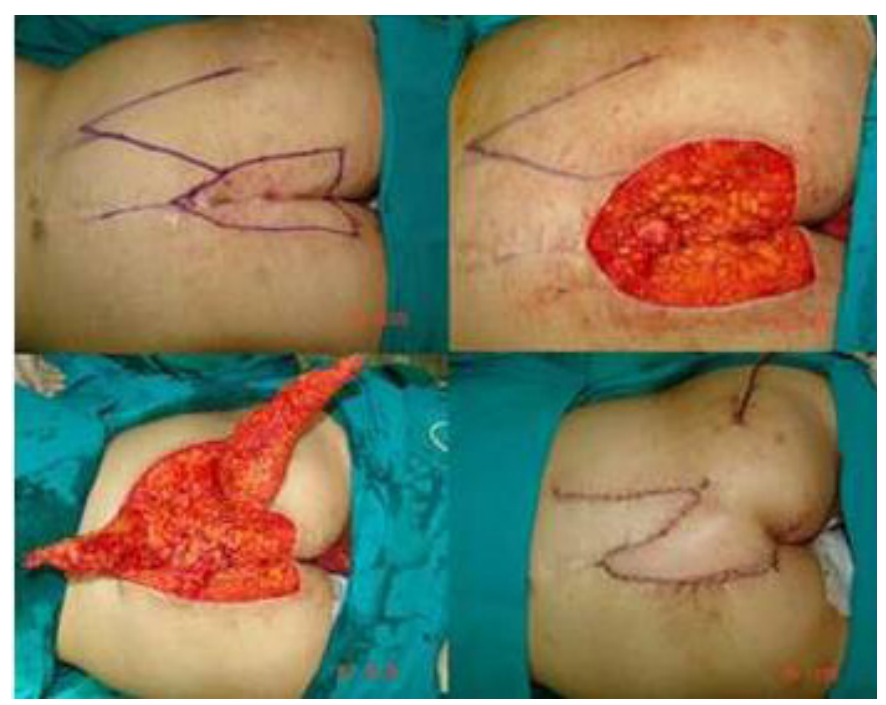

Lezyonlar en sik perianal/genital $(n=35, \% 41,8)$ bölgede yerleşim gösterirken, bunu sirasiyla koltuk altı $(\mathrm{n}=21, \% 25.6)$, gluteal bölge $(\mathrm{n}=21, \% 25.6)$ ve meme çevresi ( $\mathrm{n}=3, \%$ 2.7) takip etmekteydi (Tablo 1). Perianal bölge her iki cins için de en sık yerleşim yeri olarak tespit edildi.

Birden fazla alanda lezyonu olan hastalarda Hurley sınıflandırmasına göre en ileri lezyon esas alındı. Bu sinıflamaya göre Evre 1'de 5 hasta $(\% 11,1)$ (2 erkek, 3 kadın), Evre 2' de 13 hasta (\%28,8) (8 erkek, 5 kadın) ve Evre 3'te 27 hasta (\%60) (15 erkek, 12 kadın) saptandı.

Hastalar tedavi uygulanan alanlara göre değerlendirildiğinde nükslerin \%40’ı meme bölgesinde iken \%60'ı perianal bölgede idi. Meme bölgesinde nüks gelişen 2 hastanın lezyonları Hurley evre-1'de iken, perianal nüks gelişen 3 hastadaki lezyonlar Hurley evre-3 idi .

En sık komplikasyon görülen yerler sıklık sırasına göre perianal bölge, kasık ve koltuk altı idi (Tablo 2). 
Tablo 1: Hidradenitis süppürativalı hastaların lezyonlu bölgeleri

\begin{tabular}{|l|l|l|l|}
\hline \multicolumn{2}{|l|}{$\begin{array}{l}\text { Etkilenen alan- Erkek (n: }) \\
\text { lar }\end{array}$} & Kadın (n: ) & $\begin{array}{l}\text { Tüm Hasta- } \\
\text { lar }\end{array}$ \\
\hline Koltuk altı & $13(\% 26)$ & $8(\% 26,6)$ & $21(\% 26,2)$ \\
\hline Meme çevresi & $0(\% 0)$ & $3(\% 10)$ & $3(\% 5)$ \\
\hline Perineal/ genital & $23(\% 46)$ & $12(\% 40)$ & $35(\% 43,7)$ \\
\hline Glutea-uyluk & $14(\% 28)$ & $7(\% 23,3)$ & $21(\% 26,2)$ \\
\hline TOPLAM* & $50(\% 100)$ & $30(\% 100)$ & $80(\% 100)$ \\
\hline
\end{tabular}

Toplamda 8 hastada 18 komplikasyon gözlendi.

Lezyonların 36'sında geniş ve derin eksizyonu takiben oluşan defekt alanları lokal flepler ile kapatılırken, konulmaktadır $(11,12)$

hastalığın başlama yaşı erkeklerde ortalama 23,4 (SD: 5,6) ve kadinlarda ortalama 19,7 (SD: 6,0) olarak bulundu. $\mathrm{Bu}$ veriler literatür ile uyumlu görülmektedir.

Etyolojisine bakıldığında multifaktöriyel olup hormonal faktörler, diabetes mellitus, sigara kullanımı, kötü hijyen öne çıkan nedenler arasındadır. Bazı yayınlarda otozomal dominant aile geçişi de tanımlanmıştır. Yerleşim yeri olarak en sık aksiller, inguinoperineal, gluteal, intermammarial, ense ve uyluk iç yüzünde görülmektedir. Koltukaltı lokalizasyonunun sıklı̆̆1 kadınlarda artmış olarak görülürken, kasık bölgesi ve perianal yerleşimli lezyonlara erkeklerde daha sık rastlanmaktadır (13-18).

HS tanısı primer olarak fizik muayene ile Hidradenitis süpürativa tedavisinde önemli

Tablo 2: Lezyon tutulum bölgelerine göre komplikasyon oranları

\begin{tabular}{|l|c|c|c|c|c|c|}
\hline \multicolumn{2}{|c|}{ Enfeksiyon } & $\begin{array}{l}\text { Yara açıl- } \\
\text { ması }\end{array}$ & Kısmi Flep nekrozu & Kısmi Deri greft kaybı & Nüks & Toplam \\
\hline Koltuk altı & 0 & 1 & 3 & 0 & 0 & 4 \\
\hline Meme & 0 & 0 & 0 & 0 & 2 & 2 \\
\hline Perineal & 2 & 3 & 1 & 2 & 3 & 11 \\
\hline $\begin{array}{l}\text { Glutea-uy- } \\
\text { luk }\end{array}$ & 0 & 1 & 0 & 0 & 0 & 1 \\
\hline Toplam & 3 & 5 & 4 & 2 & 5 & 18 \\
\hline
\end{tabular}

16lezyonun eksizyonu sonrası oluşan defekt alanları kısmi kalınlıklı deri greftleri ile kapatıldı. 26 lezyona eksizyon sonrası primer onarım yapıldı (Resim 5). Perianal ve inguinal yerleşimli lezyonu olan iki hastada eksizyon sonrası defekt alanı açık bırakılarak pansumanlarla takip edildi. (Tablo 3).

Tablo 3: Lezyon tutulum alanlarına göre rekonstrüksiyon yöntemleri

\begin{tabular}{|l|c|c|r|r|}
\hline & primer & Sekonder & Greft & flep \\
\hline Koltuk altı & 6 & 0 & 10 & 5 \\
\hline Meme çevresi & 2 & 0 & 0 & 1 \\
\hline Perineal bölge & 12 & 1 & 2 & 14 \\
\hline Gluteal- uyluk & 6 & 1 & 4 & 16 \\
\hline Toplam & 26 & 2 & 16 & 36 \\
\hline
\end{tabular}

\section{TARTIŞMA}

Hidradenitis supurativa, apokrin bez duktusunun keratin tıkaciyla tıkanması sonucu duktal dilatasyon ve glandüler komponentte staz gelişimi nedeniyle ortaya çıkmaktadır. Bunu sekonder enfeksiyon gelişimini takiben aktif folikülit oluşumu ve daha sonra da bezlerin rüptürü ile enfeksiyonun ciltaltı yağlı dokuda yayılımı izler. Hastalığın püberteden önce ve 40 yaşından yaşından sonra ortaya çıkması nadirdir (1-8). Bizim hastalarımızda olan, nüks olmaksızın hastalı̆̆ın tedavi edilebilmesi, olası komplikasyonların önlenmesi ve hastanın yaşam standardının yükseltilmesidir (13-15). Hidradenitis süpürativa’da tedavi hastalığın bulguları ve derecesine göre belirlenmektedir. Erken evre hastalara genellikle tıbbi tedaviler uygulanırken, medikal tedavinin başarısız olduğu durumda cerrahi tedavi kaçınılmaz olmaktadır. Ancak kronikleşen hidradenitis süpürativa zemininda skuamoz hücreli kanser gelişme ihtimali göz önünde bulundurulmalı ve cerrahi için geç kalınmamalıdır (16). Bizim hastalarımızda hastalığın ilk oluşmasından geniş cerrahiye kadar geçen süre erkek hastalarda 19,8 yil iken bu süre kadınlarda 9,4 yıl idi. Hastalarımızın yarısindan fazlasinda $(\mathrm{n}=24, \% \quad 61,5)$ önceden tekrarlayan ve iyileşmeyen lezyonlar nedeniyle çeşitli tıbbi tedavi yöntemleri uygulanmıştı.

Cerrahi tedavide başarıyı kıllı derinin, yağ dokusunun, apokrin bezlerin, subkutan abselerin ve sinüs traktuslarının komplet rezeksiyonu belirlemektedir $(8,16,17)$.

Soldin ve arkadaşları koltuk altında apokrin bez dağılımını dikkate alarak yaptıkları bir çalışmada, koltuk altı bölgede kıl foliküllerini içeren dokunun 2 $\mathrm{cm}$ ilerisinden yaptıkları eksizyonlardan sonra nüks görülmediğini ifade etmişlerdir (15,18-22).

Parks ve arkadaşlarının yaptığı derlemede tedavinin sağlanabilmesi için $2 \mathrm{~cm}$ geniş sınırla eksizyonun yeterli 
olduğu ayrıca derinlik olarak da fasyaya kadar inilmesi gerektiğini ya da en azından $0,5 \mathrm{~cm}$ sağlam yağ dokunun da çıarılacak şekilde radikal cerrahi eksizyonun yapılması gerektiğini vurgulamıştır $(23,24)$.

$\mathrm{Bu}$ çalışmadan elde ettiğimiz bulgular hidradenitis süpürativalı hastalarda lezyonun hastalıklı sağlam deri sınırından itibaren $2 \mathrm{~cm}$ güvenlik sınırıyla çıkarılmasının hastalığı tedavi edip kür sağladığını göstermiştir. Ayrıca bu çalışma, nükslerin önlenmesinde hastalığın evresinden ve defektin nasıl kapatıldığından çok çıkarılan hastalıklı dokunun derinlik ve genişliğinin daha önemli rol oynadığını göstermiştir.

Nükslerin görüldügü 5 hastanın 3'ünde primer onarım yapılmış olması dikkat çekicidir. Nüksler, erken evre olmasına rağmen sinırlı cerrahi uygulanan intermammarial bölgedeki evre 1 ve 2 lezyonda ve rektuma yakın yerleşimli evre 3 lezyonu olan hastalarda görülmüştür. Bunun nedeni olarak hipertrofik skar dokusu oluşumundan çekinilen sternum bölgesinde ve sfinkter fonksiyon kaybindan korkulan perineal bölgelerde sınırlı cerrahi uygulanmasıdır.

Hidradenitis süpürativa olgularında total eksizyon sonrası primer kapatılamayacak kadar geniş defektlerde, sekonder iyileşmeye bırakma, greftleme, lokal flepler ile kapama literatürde önerilmiş tedavi seçenekleridir (25). $\mathrm{Bu}$ çalışmada, koltuk altı, gluteal ve perineal bölgedeki lezyonlara eksizyon sonrası sıklıkla flep ile onarım uygulandığı, skrotal bölgedeki 4 lezyonun hepsine (\% 100) ve kasık bölgesindeki 5 lezyondan 4'üne (\% 80'i) eksizyon sonrası primer onarım yapıldığı görülmektedir. Eksizyon sonrası defekti sekonder iyileşmeye bırakma eğiliminde olan ve erken nükslere anında eksizyon yapılabileceğini belirten çalışmalar bildirilmiştir (26). Bununla birlikte bu yaklaşım geç yara iyileşmesi ve kontraktürlere sebep olabilir. Özellikle perianal bölge gibi yerlerde aşamalı cerrahi uygulanıp tüm odakların temizlendiğinden emin olunduktan sonra rekonstrüksiyon yapilabilir. Bizim sekonder iyileşmeye bıraktığımız perianal bölgede lezyonu olan 2 hastada da kontraktür oluşumu görülmedi.

Hidradenitis süpürativa ayırıc1 tanısinda karbonkül, lenfadenit, enfekte bartolin kisti bulunurken sistemik hastalık olan ve sinüs ve fistüllerle giden aktinomikoz, kedi tırmığı hastalığı, tüberküloz lenfogranuloma venerum, Crohn hastalı̆ğ granuloma inguinale ve tüberküloz gibi hastalıklar bulunur $(27,28)$.

Hidradenitis süpürativalı hastaları tedaviye yönlendiren temel sebep yaşam kalitesinin bozulması ve psikolojik sorunlara kadar geniş yelpazede sağllk problemlerine sebep olmasıdır. ${ }^{29,30}$ Hasta sorgulamasında bütün hastaların özellikle kadın hastaların bu hastalıktan dolayı psikolojik olarak rahatsızlık duyduklarını ve topluluklara fazla katılamadıklarını ifade etmişlerdir. Biri erkek biri kadın iki hastanın psikolojik tedavi gördükleri belirlenmiştir.

\section{SONUÇ}

Hidradenitis süpurativa yaşam kalitesini bozan bir hastalıktır. Hastalık sağlıklı görünen cilt altında sinüs traktlarıyla devam ettiği için erken evrelerde bile gecikmeden geniş ve derin cerrahi eksizyon nükslerin önlenmesi için gereklidir. Bununla birlikte geniş cerrahi sınırla eksizyonu, lezyonun sıkça yerleştiği perineal bölgelerde gerçekleștirmek zordur. Özellikle inguinal ve perianal/perineal lezyonlarda anüsle vulva ya da anüsle skrotum arasında bir miktar cilt bırakmak gerektiğinden nüksün bu alanlarda daha sık olması kaçınılmazdır. Perineal bölgede geniş cerrahi eksizyon özellikle rektuma yakın alanlarda sfinkter kaybı ile sonuçlanabileceğinden bu alanlarda kür sağlanabilmesi amacıyla kalıcı kolostomi açılma olasılığ 1 ve komplikasyonlar hakkında hastanın önceden bilgilendirilmesi gereklidir.

\section{KAYNAKLAR}

1- Werth JMVD, Williams HC, Raeburn JA. The clinical genetics of hidradenitis suppurativa revisited. $\mathrm{Br} \mathrm{J}$ Dermatol 2000; 142: 947-953.

2- Barth JH, Layton AM, Cunliffe WJ. Endocrine factors in pre and postmenopausal women with hidradenitis suppurativa. Br J Dermatol 1996; 134: 1057-9.

3- Slade DEM, Powell BW, Mortimer PS. Hidradenitis suppurativa: pathogenesis and management. $\mathrm{Br} \mathrm{J}$ Plast Surg 2003; 56: 451-61.

4- Konig A, Lehman C, Rompel R, Happel R. Cigarette smoking as a triggering factor of hidradenitis suppurativa. Dermatology 1999; 198: 261-4.

5- Camisa C, Sexton C, Friedman C. Treatment of hidradenirtis suppurativa with combination hypothalamic-pituitary-ovarian and adrenal supression: a case report . J Reprod Med 1989; 34: 543-6.

6- Ather S, Chan DSY, Leaper DJ, Harding KD. Surgical treatment of hidradenitis suppurativa: case series and review of the literature. Int Wound J 2006; 3: 159-169.

7- Mortimer PS, Lunniss PJ. Hidradenitis suppurativa. J R Soc Med. 2000; 93: 420-2.

8- Anonymus. Calprotectin, zinc and abscess. Lancet 1991; 338: 855-6.

9- Brocard A, Knol AC, Khammari A, Dreno B. Hidradenitis suppurativa and zinc: a new therapeutic approach. A pilot study. Dermatology 2007; 214: 325-7.

10- Akbaş H, Karacaoğlan N, Uysal A. Hydradenitis Supurativa Case Report. J Exp Clin Med 1997; 14: 69-72.

11- Fitzsimmons JS, Guilbert PR. Evidence of genetic factors in hidradenitis suppurativa. Br J Dermatol 1985; 113: 1-8.

12- Kırçuval D, Tüzün B, Korkut C. A Case Of Follicular Occlusion Triad. Turkiye Klinikleri J Med Sci 2004, 24: 291-4.

13-Attanoos RL, Appleton MAC, Douglas-Jones AG. The pathogenesis of hidradenitis suppurativa: a closer look at apocrine and apo-eccrine glands. $\mathrm{Br} \mathrm{J}$ Dermatol 1995; 133: 254-8.

14- Pedraz J, Dauden E. Practical management of hidradenitis suppurativa. Actas Dermosifiliogr. 2008; 99: $101-10$ 
15-Soldin MG, Tulley P, Kaplan H, Hudson DA, Grobbelaar AO. Chronic axillary hidradenitis-the efficacy of wide excision and flap coverage. Br J Plast Surg 2000; 53: 434-6.

16- Rompel R, Petres J. Long-term results of widesurgical excision in 106 patients with hidradenitis suppurativa. Dermatol Surg 2000; 26: 638-4.

17- Menderes A, Sunay O, Vayvada H, Yilmaz M. Surgical management of hidradenitis suppurativa. Int J Med Sci 2010; 7: 240-247.

18-Bieniek A, Matusiak L, Okulewicz-Gojlik D, Szepietowski JC. Surgical treatment of hidradenitis suppurativa: experiences and recommendations. Dermatol Surg 2010; 36: 1998-2004.

19- Bohn J. Svenson H. Surgical treatment of hidradenitis suppurtaiva. Scand J Plast Reconstr Surg Hand Surg 2001; 35: 305-9.

20- Jemec GB. Effect of localized surgical excisions in hidradenitis suppurativa. J Am Acad Dermatol 1988; 18: 1103-7.

21-Hurley HJ. Axillary hyperhidrosis, apocrine bromhidrosis, hidradenitis suppurative, and familial benign pemfigus: Surgical approach. In: Roenigk RK, Roenigk HHJ, editors. Dermatol Surg. Principles and practice.1st edt. New York: Marcel Dekker; 1989. p. 717-43.

22- Wolkenstein P, Loundou A, Barrau K Auquier P,
Revuz J. Quality of life impairment in hidradenitis suppurativa: a study of 61 cases. J Am Acad Dermatol 2007; 56: 621-623.

23-Watson JD. Hidradenitis suppurativa-a clinical review. Br J Plast Surg 1985; 38: 567-9.

24- Parks RW, Parks TG. Pathogenesis, clinical features and management of hidradenitis suppurativa. Ann R Coll Surg Engl 1997; 79: 83-9.

25- Morgan WP, Harding KG, Hughes LE. A comparison of skin grafting and healing by granulation, following axillary excision for hidradenitis suppurativa. Ann R Coll Surg Engl 1983; 65: 235-6.

26-Shah N. Hidradenitis suppurativa: a treatment challenge. Am Fam Physician 2005; 72: 1547-52.

27- Church JM, Fazio VW, Lavery IC, Oakley JR, Milsom JW. The differential diagnosis and comorbidity of hidradenitis suppurativa and perianal Crohn's disease. Int J Colorectal Dis 1993; 8: 117-9.

28-Williams ST, Busby RC, DeMuth RJ, Nelson H. Perineal hidradenitis suppurativa: presentation of two unusual complications and a review. Ann Plast Surg 1991; 26: 456-62.

29- Kagan RJ, Yakuboff KP, Warner P, Warden GD. Surgical treatment of hidradenitis suppurativa: A 10year experience. Surgery 2005; 138: 734-40.

30-Esmann S,Jemec GB. Psychosocial Impact of Hidradenitis Suppurativa: A Qualitative Study Acta Derm Venereol 2011: 91: 328-332 